\title{
Hypopharyngeal Cancer cN3 TNM Finding v8
}

National Cancer Institute

\section{Source}

National Cancer Institute. Hypopharyngeal Cancer cN3 TNM Finding v8. NCI Thesaurus. Code C132954.

Hypopharyngeal cancer with metastasis in a lymph node larger than $6 \mathrm{~cm}$ in greatest dimension and ENE(-); or metastasis in any node(s) and clinically overt ENE(+). (from AJCC 8th Ed.) 